\title{
Design, synthesis and cytotoxicity of novel N-benzylpiperidin-4-one oximes on human cervical cancer cells
}

\author{
SOMESHWAR D DINDULKAR ${ }^{\mathrm{a}, \mathrm{b}}$, IRA BHATNAGAR ${ }^{\mathrm{c}}$, RUPESH L GAWADE $^{\mathrm{d}}$, \\ VEDAVATI G PURANIK ${ }^{\mathrm{d}}$, SE-KWON KIM ${ }^{\mathrm{a}}$, DONG HYUN ANH ${ }^{\mathrm{e}}$, \\ PARAMASIVAM PARTHIBAN ${ }^{\mathrm{f}}$ and YEON TAE JEONG ${ }^{\mathrm{a}, *}$ \\ ${ }^{a}$ Department of Image Science and Engineering, Pukyong National University, Busan 608737 , \\ Republic of Korea \\ bInstitute of MGM's Jawaharlal Nehru Engineering College, Aurangabad, 431 003, India \\ ${ }^{\mathrm{c}}$ Nanotheranostics Laboratory, Centre for Cellular and Molecular Biology, Hyderabad 500 007, India \\ ${ }^{\mathrm{d}}$ Center for Materials Characterization, National Chemical Laboratory, Pune 400008 , India \\ ${ }^{e}$ Department of Food Science and Technology, Pukyong National University, Busan 608737 , \\ Republic of Korea \\ ${ }_{\mathrm{f}}$ Department of Chemistry, Veltech Multitech Dr. Rangarajan Dr. Sakunthala Engineering College, Chennai \\ 600 062, India \\ e-mail: ytjeong@pknu.ac.kr
}

MS received 28 May 2012; revised 13 January 2014; accepted 17 January 2014

\begin{abstract}
A series of fifteen diversified N-benzylpiperidin-4-one oximes were synthesized and characterized by their NMR spectral data. Additionally, single-crystal XRD analysis was performed for the representative symmetrically and unsymmetrically substituted molecules. All the synthesized oximes from unsymmetrical ketones existed as E-isomer as witnessed by their NMR and XRD data. Among the synthesized target compounds that evaluated for their in vitro cytotoxicity against human cervical carcinoma (HeLa) cells, five compounds were potent with $\mathrm{IC}_{50}<17 \mu \mathrm{M}$. 1-Benzyl-2,6-bis(4-isopropylphenyl)-3-methylpiperidin-4-one oxime $3 \mathrm{c}$ with an $\mathrm{IC}_{50}$ of $13.88 \mu \mathrm{M}$ was found to be the best active compound as depicted by the microscopic analysis.
\end{abstract}

Keywords. N-benzylpiperidin-4-one oximes; cytotoxicity, HeLa cells; single-crystal XRD.

\section{Introduction}

Cervical cancer, a slow growing squamous cell carcinoma, caused by human papillomavirus (HPV) is the second most common cancer after breast cancer that affects women. ${ }^{1-3}$ Although a number of new and effective medicines have been implemented in the cancer arena, some limitations exist in present therapeutic regime such as target non-specificity, associated side effects and lack of potency. ${ }^{4,5}$ Hence the need of new, safe and potent anticancer compounds is motivating the medicinal chemists towards the invention and development of effective molecules. Considering the reports on piperidin-4-one heterocycles (figure 1a and b) as good cytotoxic agents, ${ }^{6-10}$ we synthesized some $\mathrm{N}$ benzylated piperidin-4-one oximes (figure 1c) as target molecules.

In fact, the chalcones with piperidone core (a) are the heterocyclic analogs of $\alpha, \beta$-unsaturated ketones (curcumin). They are reported to possess a strong cytotoxic

\footnotetext{
*For correspondence
}

and anticancer property over a wide range of cancer cells. ${ }^{11-13}$ The structure-activity relationship (SAR) studies from differently substituted piperidones reveal that the nature of functional groups and position of the substituents are important to effect the biological actions. ${ }^{6-10}$

\section{Experimental}

\section{$2.1 \quad$ NMR experiments}

All 1D NMR spectra of the synthesized compounds were recorded on Jeol JNM ECP 400 NMR spectrometer at $294 \mathrm{~K}$. The ${ }^{1} \mathrm{H}$ and ${ }^{13} \mathrm{C}$ NMR spectra were measured, respectively $0.03 \mathrm{M}$ and $0.05 \mathrm{M}$ solutions in $\mathrm{CDCl}_{3}$ with TMS as internal reference in $5 \mathrm{~mm}$ NMR tubes. The pulse conditions were as follows: ${ }^{1} \mathrm{H}$ NMR spectra: SF 399.78 MHz, AQ $2.73 \mathrm{~s}$, NS 32, DS 0, SW $5998.8 \mathrm{~Hz}$, pulse $4.65 \mu \mathrm{s}$, angle $45^{\circ}$, width $9.3 \mu \mathrm{s}$, DR $0.366 \mathrm{~Hz}, \mathrm{RD} 5 \mathrm{~s}$, RG 13, data points 16384, pre scan delay $1 \mathrm{~s} ;{ }^{13} \mathrm{C}$ NMR spectra: SF $100.52 \mathrm{MHz}$, AQ $1.25 \mathrm{~s}$, NS 250, DS 4, SW 26178.01 Hz, Pulse $3.13 \mu \mathrm{s}$, 


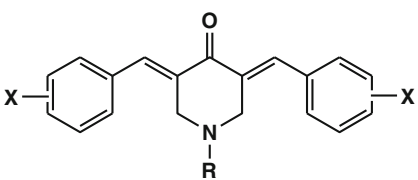

(a)

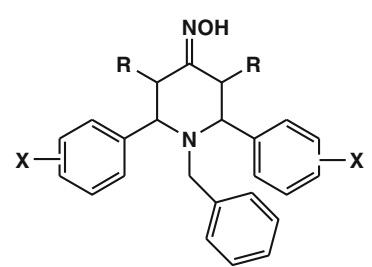

(c)

Target Compounds

Figure 1. General structure of literature compounds (a) and (b) with good cytotoxicity against various cell line and synthesized target compounds (c).

angle $30^{\circ}$, width $9.4 \mu \mathrm{s}$, DR $0.798 \mathrm{~Hz}$, RD $1 \mathrm{~s}$, RG 25 , data points 32768 , pre scan delay $1 \mathrm{~s}$. The ${ }^{1} \mathrm{H}$ and ${ }^{13} \mathrm{C}$ chemical shift values are given in $\delta$ scale (ppm) and referred to TMS, via the solvent signals $\left({ }^{1} \mathrm{H}\right.$, residual $\mathrm{CHCl}_{3}$ at $7.26 \mathrm{ppm} ;{ }^{13} \mathrm{C}_{,} \mathrm{CHCl}_{3}$ at $77.16 \mathrm{ppm}$ ). Coupling constants $J$ are reported in $\mathrm{Hz}$.

\subsection{Single-crystal XRD}

The X-ray diffraction quality crystals of $\mathbf{3 d}$ and $\mathbf{3 n}$ were obtained by slow evaporation from chloroform and the crystal structure was determined by the X-ray diffraction data collected on a Bruker SMART APEX CCD diffractometer. ${ }^{14} \mathrm{X}$-ray analysis (3d and $\mathbf{3 n}$ ) were performed at $296 \mathrm{~K}$ temperature using $\mathrm{Mo}-\mathrm{K} \alpha$ radiation $(\lambda=0.7107 \AA)$ to a maximum $\theta$ range of $25^{\circ}$. Crystal to detector distance $6.05 \mathrm{~cm}, 512 \times 512$ pixels/frame, oscillation/frame $-0.3^{\circ}$, maximum detector swing angle $=-30.0^{\circ}$, beam centre $=(260.2,252.5)$, in plane spot width $=1.24$, SAINT integration. SHELX97 (ShelxTL) was used for structure solution and full matrix least squares refinement on $F^{2} \cdot{ }^{15}$ Hydrogen atoms were included in the refinement as per the riding model.

\subsection{General procedure for the synthesis of 2,6-diarylpiperidin-4-ones (1a-1o)}

All the parent 2,6-diarylpiperidin-4-ones were synthesized by adopting the literature precedent of Noller and Baliah ${ }^{16}$ through the condensation of respective ketones, aldehydes and ammonium acetate in 1:2:1 ratio. All the synthesized piperidin-4-ones are in good agreement with their NMR data reported earlier. ${ }^{17-19}$

\subsection{General procedure for the synthesis of 1-benzyl-2,6-diarylpiperidin-4-ones (2a-2o)}

A mixture of respective 2,6-diarylpiperidin-4-ones $(0.01 \mathrm{~mol})$, anhydrous potassium carbonate $(0.02 \mathrm{~mol}$, $2.76 \mathrm{~g})$ and benzyl bromide $(0.015 \mathrm{~mol}, 1.78 \mathrm{~mL})$ in DMF $(20 \mathrm{~mL})$ was stirred at room temperature for 12-36 h. Progress and completion of the reactions were monitored by the TLC. After the completion, an excess of ice-cold water was added and extracted with dichloromethane $(3 \times 15 \mathrm{~mL})$. The organic layer, thus separated was thrice washed with brine solution $(3 \times 10 \mathrm{~mL})$ and dried over anhydrous $\mathrm{Na}_{2} \mathrm{SO}_{4}$. Then the organic layer was concentrated in rota to obtain the crude product, followed by purification on silicagel (Merck 230-400 mesh), using $n$-hexane and ethyl acetate mixture, afforded the pure 1-benzyl-3-alkyl-2,6diarylpiperidin-4-ones $\mathbf{2 a - 2 o}$ in good yields $87-92 \%$. All the N-benzylated piperidine-4-ones were characterized by their analytical and spectral data, and confirmed with previous reports. ${ }^{18,19}$

\subsection{General procedure for the synthesis of 1-benzyl-2,6-diarylpiperidin-4-one oximes (3a-3o)}

A mixture of 1-benzyl-2,6-diarylpiperidin-4-one $(0.002 \mathrm{~mol})$, hydroxylamine hydrochloride $(0.003 \mathrm{~mol})$ and sodium acetate trihydrate $(0.003 \mathrm{~mol})$ were dissolved in ethanol $(5 \mathrm{~mL})$. The resulting reaction mixture was refluxed and the formation of the desired compound monitored by TLC analysis. After completion of reaction, solvent was evaporated using rota-vapour, water was added and extracted with ethyl acetate $(3 \times 15 \mathrm{~mL})$. The organic layer was dried (anhydrous $\mathrm{Na}_{2} \mathrm{SO}_{4}$ ) and the solvent were evaporated on a rota-vapour. In a few cases, further purification was required; hence, they either recrystallized using ethanol or purified by column chromatography.

\subsection{Cytotoxicity assay (MTT assay)}

The HeLa cell line was obtained from American Type Culture Collection (Manassas, VA, USA). Dulbecco's Modified Eagle's Medium (DMEM) was pur-

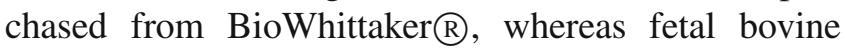
serum (FBS) and other cell culture materials were purchased from Gibco BRL Life Technologies, USA. Paraformaldehyde and bisbenzimide Hoechst 33342 stain were procured from Sigma-Aldrich Corp., St. Louis, MO, USA, and MTT [3-(4,5-dimethylthiazol2-yl)-2,5-diphenyltetrasolium bromide] was purchased from Biosesang Inc., Korea. 
Mononuclear cells from peripheral blood of healthy adults was used to isolated PBMCs using FicollHypaque (Pharmacia, Freiburg, FRG) density gradient centrifugation. ${ }^{20}$ Cells were cultured in T-75 tissue culture flasks (Nunc, Denmark) at $37^{\circ} \mathrm{C}$ in a $5 \% \quad \mathrm{CO}_{2}$ humidified incubator using appropriate media supplemented with DMEM containing 10\% heat-inactivated FBS, 100 units/mL Penicillin and $100 \mu \mathrm{g} / \mathrm{mL}$ Streptomycin. Cells were seeded in a 96 well microtiter plate containing $100 \mu \mathrm{L}$ medium at a final density of $2 \times 10^{4}$ cells/well at identical conditions. After overnight incubation, the cells were treated with different concentrations of test compounds $(6.25-100 \mu \mathrm{g} / \mathrm{mL})$ or DMSO (carrier solvent) in a final volume of $200 \mu \mathrm{L}$. After $24 \mathrm{~h}, 10 \mu \mathrm{L}$ of MTT $(5 \mathrm{mg} / \mathrm{mL})$ was added to each well and the plate was incubated at $37^{\circ} \mathrm{C}$ in the dark for $4 \mathrm{~h}$. Then the media along with MTT was removed and the formazan crystals were solubilised by adding DMSO (100 $\mu \mathrm{L} /$ well). Finally, the reduction of MTT was quantified by reading the absorbance at $570 \mathrm{~nm}$ by GENios $₫$ microplate reader (Tecan Austria GmbH). Effects of the test compounds on cell viability were calculated using cells treated with DMSO as control. The data were subjected to linear regression analysis and the regression lines were plotted for the best straight-line fit.

\subsection{Altered morphology study}

The altered morphology of exposed cells $\left(1 \times 10^{5}\right.$ cells/well) at $\mathrm{IC}_{50}$ concentration was studied after $24 \mathrm{~h}$ using phase contrast microscope (DMI6000B, Leica Microsystems, Wetzlar, Germany). Subsequently, the cells were Hoechst stained to observe the nuclear/chromosomal condensation that occurred after treatment with the test compound. For staining the cells, 96 well cell culture plates were used to culture the cells $\left(1 \times 10^{4}\right.$ cells/well $)$ in three replicates to treat with the ideal lead compound 3c. Then the cells were incubated at $37^{\circ} \mathrm{C}$ overnight and the media was removed to wash the cells twice with phosphate buffered saline (PBS) and fixed with $4 \%$ paraformaldehyde in PBS for one day at $-4{ }^{\circ} \mathrm{C} .{ }^{10}$ Further, the cells were stained with nuclear binding dye Hoechst 33342 ( $1 \mu \mathrm{g} / \mathrm{mL}$ of the fluorescent DNA-binding dye, bisbenzimide Hoechst 33342 stain was added to the fixed cells and incubated for $20 \mathrm{~min}$ at room temperature) to expose the nuclear condensation/aggregation due to the effect of the compound 3c. Similarly, PI stock solution $(1 \mathrm{mg} / \mathrm{mL})$ was diluted to $1: 3000$ with $1 \mathrm{X}$ PBS and added to the cells for allowing the stain to get permeated by the dead cells. The Hoechst and PI stained cells were visualized and photographed under fluorescence microscope (CTR 6000; Leica, Wetzlar, Germany).

\subsection{Annexin V-PI dual staining to access apoptosis}

Annexin V-FITC/PI dual staining was performed to access the level of apoptosis and cell death in HeLa cells treated with $\mathrm{IC}_{50}$ concentration $13.88 \mu \mathrm{M}$ of compound 3c, $24 \mathrm{~h}$ post treatment. Annexin V-FITC and PI staining solutions used were components of the FITC annexin V Apoptosis Detection Kit (BD Pharmingen $^{\mathrm{TM}}$ ). The staining procedure was followed as per manufacturer's instructions. Briefly, HeLa cells incubated at $37^{\circ} \mathrm{C}$ with $5 \% \mathrm{CO}_{2}, 0,4,12$ and $24 \mathrm{~h}$ post treatment with $13.88 \mu \mathrm{M}$ of compound $\mathbf{3 c}$., were harvested using $1 \mathrm{X}$ Trypsin-EDTA solution prepared in serum free DMEM. Cells were washed twice with cold PBS and then resuspended in $1 \mathrm{X}$ binding buffer (provided with the kit) at a concentration of $1 \times 10^{6}$ cells $/ \mathrm{ml} .100 \mu \mathrm{l}$ of this solution $\left(1 \times 10^{5}\right.$ cells $)$ was transferred to a $5 \mathrm{ml}$ culture tube followed by addition of $5 \mu \mathrm{l}$ of FITC Annexin V, gentle vortexing and incubation for $15 \mathrm{~min}$ at room temperature $\left(25^{\circ} \mathrm{C}\right)$ in dark. $2 \mu \mathrm{l}$ of PI staining solution was then added to these Annexin V-FITC labelled cells and incubated further for $5 \mathrm{~min}$ under similar conditions. Finally, $400 \mu \mathrm{l}$ of $1 \mathrm{X}$ binding buffer was added to each tube. Cells were mounted on glass slides and observed under fluorescence microscope (CTR 6000; Leica, Wetzlar, Germany).

\section{$2.9{ }^{1} \mathrm{H}$ and ${ }^{13} \mathrm{C}$ NMR data of the target compounds}

2.9a 1-Benzyl-3methyl-2,6-diphenylpiperidin-4-one oxime (3a, $\left.\mathbf{C}_{\mathbf{2 5}} \mathbf{H}_{\mathbf{2 6}} \mathbf{N}_{\mathbf{2}} \mathbf{O}\right)$ : Faint pink solid; Yield: 89\%; m.p.: $176-178^{\circ} \mathrm{C}$; ${ }^{1} \mathrm{H}$ NMR (400 MHz, $\mathrm{CDCl}_{3}$ ): $\delta=8.59(\mathrm{~s}, \mathrm{OH}), 7.50(\mathrm{t}, J=9.7 \mathrm{~Hz}, 4 \mathrm{H}), 7.37-7.33$ (m, 4H), 7.32-7.24 (m, 2H), $7.10(\mathrm{t}, J=3.1 \mathrm{~Hz}, 3 \mathrm{H})$, 6.83-6.77 (m, 2H), 3.73 (dd, $J=3.5,11.5 \mathrm{~Hz}, \mathrm{H}-6 \mathrm{a})$, $3.57\left(\mathrm{~d}, J=15.0 \mathrm{~Hz}, 1 \mathrm{H}\right.$ of $\left.\mathrm{N}-\mathrm{CH}_{2}\right), 3.48-3.36(\mathrm{~m}, 3 \mathrm{H}$ of $\mathrm{H}-2 \mathrm{a}, \mathrm{H}-3 \mathrm{a}$ and $1 \mathrm{H}$ of $\mathrm{N}-\mathrm{CH}_{2}$ merged), 2.58-2.51 (m, H-5a), 2.14 (dd, $J=11.7,13.9 \mathrm{~Hz}, \mathrm{H}-5 \mathrm{e}), 0.76$ (d, $J=6.6 \mathrm{~Hz}, \mathrm{CH}_{3}$ at $\left.\mathrm{C}-3\right) \mathrm{ppm} ;{ }^{13} \mathrm{C} \mathrm{NMR}(100.52 \mathrm{MHz}$, $\left.\mathrm{CDCl}_{3}\right): \delta=159.64(\mathrm{C}-4), 144.13\left(\mathrm{C}-6^{\prime}\right), 142.54$ (C-2'), 136.70 (N-Bn ipso carbon), 130.08, 129.10, $128.73,128.46,127.84,127.64,127.41,126.67,72.36$ (C-2), 63.96 (C-6), $53.43\left(\mathrm{~N}-\underline{C H}_{2}-\mathrm{Ph}\right), 43.90$ (C-3), 35.06 (C-5), $12.84\left(\underline{\mathrm{CH}}_{3}\right.$ at $\left.\mathrm{C}-3\right) \mathrm{ppm}$; and HRMS: m/z calculated: 370.2045 , found: 370.4231 .

2.9b 1-Benzyl-3-methyl-2,6-bis(4-methylphenyl)piperidin-4-one oxime $\left(\mathbf{3 b}, \mathbf{C}_{27} \mathbf{H}_{30} \mathbf{N}_{\mathbf{2}} \mathbf{O}\right)$ : Off-white solid; 
Yield: $78 \%$; m.p.: $150-152{ }^{\circ} \mathrm{C} ;{ }^{1} \mathrm{H}$ NMR $(400 \mathrm{MHz}$, $\left.\mathrm{CDCl}_{3}\right): \delta=9.45(\mathrm{~s}, \mathrm{OH}), 7.40-7.35(\mathrm{~m}, 4 \mathrm{H}), 7.15-$ $7.09(\mathrm{~m}, 7 \mathrm{H}), 6.83-6.82(\mathrm{~m}, 2 \mathrm{H}), 3.67$ (dd, $J=3.3$, $11.7 \mathrm{~Hz}, \mathrm{H}-6 \mathrm{a}), 3.56$ (d, $J=15.0 \mathrm{~Hz}, 1 \mathrm{H}$ of $\mathrm{N}-\mathrm{CH}_{2}$ ), 3.47-3.42 (m, 2H of $\mathrm{N}-\mathrm{CH}_{2}$ and $\mathrm{H}-2 \mathrm{a}$ merged), 3.30 (d, $J=9.8 \mathrm{~Hz}, \mathrm{H}-3 \mathrm{a}), 2.55-2.47$ (m, H-5a), 2.34 (s, 3H), $2.33(\mathrm{~s}, 3 \mathrm{H}), 2.16-2.09$ (unresolved quartet, H-5e), $0.76\left(\mathrm{~d}, J=6.6 \mathrm{~Hz}, \mathrm{CH}_{3}\right.$ at $\left.\mathrm{C}-3\right) \mathrm{ppm} ;{ }^{13} \mathrm{C} \mathrm{NMR}$ $\left(100.52 \mathrm{MHz}, \mathrm{CDCl}_{3}\right): \delta=159.81(\mathrm{C}-4), 141.12$ $\left(\mathrm{C}-6^{\prime} \mathrm{c}\right), 139.45\left(\mathrm{C}-2^{\prime} \mathrm{c}\right), 137.09\left(\mathrm{C}-6^{\prime}\right), 136.86\left(\mathrm{C}-2^{\prime}\right)$, 136.67 (N-Bn ipso carbon), 130.10, 129.35, 129.07, 127.51, 71.92 (C-2), 63.55 (C-6), $53.08\left(\mathrm{~N}-\underline{C} \mathrm{H}_{2}-\mathrm{Ph}\right)$, 43.91 (C-3), 35.27 (C-5), $21.28\left(\mathrm{CH}_{3}\right.$ at C-6d and C-2d) $12.84\left(\mathrm{CH}_{3}\right.$ at $\left.\mathrm{C}-3\right) \mathrm{ppm}$; and HRMS: $\mathrm{m} / \mathrm{z}$ calculated: 398.2358, found: 398.2833 .

2.9c 1-Benzyl-2,6-bis(4-isopropylphenyl)-3-methylpiperidin-4-one oxime $\left(\mathbf{3 c}, \mathbf{C}_{\mathbf{3 1}} \mathbf{H}_{38} \mathbf{N}_{\mathbf{2}} \mathbf{O}\right)$ : White solid; Yield: $90 \%$; m.p.: $206-208^{\circ} \mathrm{C}$; ${ }^{1} \mathrm{H}$ NMR $(400 \mathrm{MHz}$, $\left.\mathrm{CDCl}_{3}\right): \delta=7.31(\mathrm{~d}, J=8.0 \mathrm{~Hz}, 4 \mathrm{H}), 7.15(\mathrm{~d}$, $J=7.7 \mathrm{~Hz}, 2 \mathrm{H}$ ), 7.10 (unresolved dt, 5H), 6.93 (d, $J=6.9 \mathrm{~Hz}, 2 \mathrm{H}), 3.92(\mathrm{~d}, J=6.2 \mathrm{~Hz}, \mathrm{H}-6 \mathrm{a}), 3.79(\mathrm{~d}$, $J=6.2 \mathrm{~Hz}, \mathrm{H}-2 \mathrm{a}), 3.69(\mathrm{~d}, J=14.2 \mathrm{~Hz}, 1 \mathrm{H}$ of $\mathrm{N}-$ $\mathrm{CH}_{2}$ ), 3.59-3.51 (m, 2H of $\mathrm{N}-\mathrm{CH}_{2}$ and $\mathrm{H}-3 \mathrm{a}$ merged),

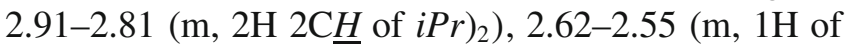
$\mathrm{H}-5 \mathrm{a}), 1.23$ (t, $J=7.5 \mathrm{~Hz}, 13 \mathrm{H}), 1.00(\mathrm{~d}, J=6.9 \mathrm{~Hz}$, $\mathrm{CH}_{3}$ at C-3) ppm; ${ }^{13} \mathrm{C}$ NMR (100.52 $\left.\mathrm{MHz}, \mathrm{CDCl}_{3}\right): \delta$ $=159.96(\mathrm{C}-4), 148.08\left(\mathrm{C}-6^{\prime} \mathrm{c}\right), 147.87\left(\mathrm{C}-2^{\prime} \mathrm{c}\right), 141.36$ $\left(\mathrm{C}-6^{\prime}\right), 139.71$ (C-2'), 136.78 (N-Bn ipso carbon), 129.89, 127.48, 126.59, 126.32, 72.73 (C-2), 64.38 (C-6), $53.89\left(\mathrm{~N}-\underline{C H}_{2}-\mathrm{Ph}\right), 43.82(\mathrm{C}-3), 35.04(\mathrm{C}-5)$, $33.90(\underline{C} \mathrm{H}$ of $\mathrm{i} P r$ at $\mathrm{C}-2 \mathrm{~d}, \mathrm{C}-6 \mathrm{~d}), 24.23\left(2{ }^{\mathrm{C}} \mathrm{H}_{3}\right.$ at C-6d), $24.16\left(2 \underline{C H}_{3}\right.$ at C-2d), $12.87\left(\underline{C H}_{3}\right.$ at $\left.\mathrm{C}-3\right)$ ppm; and HRMS: m/z calculated: 454.2984, found: 454.3362 .

2.9d 1-Benzyl-2,6-bis(4-chlorophenyl)-3-methylpiperidin-4-one oxime (3d, $\left.\mathbf{C}_{\mathbf{2 5}} \mathbf{H}_{\mathbf{2 4}} \mathbf{C l}_{\mathbf{2}} \mathbf{N}_{\mathbf{2}} \mathbf{O}\right)$ : Off-white solid; Yield: $82 \%$; m.p.: $174-176{ }^{\circ} \mathrm{C}$; ${ }^{1} \mathrm{H}$ NMR $\left(400 \mathrm{MHz}, \mathrm{CDCl}_{3}\right): \delta=7.43-7.39(\mathrm{~m}, 4 \mathrm{H}), 7.30(\mathrm{~d}$, $J=6.2 \mathrm{~Hz}, 4 \mathrm{H}), 7.11(\mathrm{~d}, J=5.5 \mathrm{~Hz}, 3 \mathrm{H}), 6.78-6.72$ $(\mathrm{m}, 2 \mathrm{H}), 3.69(\mathrm{~d}, J=7.3 \mathrm{~Hz}, \mathrm{H}-6 \mathrm{a}), 3.52-3.32(\mathrm{~m}$, $4 \mathrm{H}$ of $\mathrm{H}-2 \mathrm{a}, \mathrm{H}-3 \mathrm{a}$ and $2 \mathrm{H}$ of $\mathrm{N}_{-} \mathrm{CH}_{2}$ merged), 2.532.45 (m, H-5a), 2.14-2.06 (m, 1H), $0.75(\mathrm{~d}, J=$ $5.8 \mathrm{~Hz}, \mathrm{CH}_{3}$ at $\left.\mathrm{C}-3\right) \mathrm{ppm} ;{ }^{13} \mathrm{C} \mathrm{NMR}(100.52 \mathrm{MHz}$, $\left.\mathrm{CDCl}_{3}\right): \delta=158.92$ (C-4), 142.30 (C-6'c), 140.75 $\left(\mathrm{C}-2^{\prime} \mathrm{c}\right), 136.45$ (N-Bn ipso carbon), 133.30 (C-6'), 133.04 (C-2'), 130.27, 129.75, 129.10, 128.94, 128.71, 127.80, 126.86, 71.98 (C-2), 63.55 (C-6), 53.85 (N$\left.\mathrm{CH}_{2}-\mathrm{Ph}\right), 43.67(\mathrm{C}-3), 34.72(\mathrm{C}-5), 12.74\left(\mathrm{CH}_{3}\right.$ at C-3) ppm; and HRMS: $\mathrm{m} / \mathrm{z}$ calculated: 338.1266 , found: 338.1854 . 2.9e 1-Benzyl-2,6-bis(4-methoxyphenyl)-3-methylpiperidin-4-one oxime (3e, $\mathbf{C}_{\mathbf{2}} \mathbf{H}_{\mathbf{3 0}} \mathbf{N}_{\mathbf{2}} \mathbf{O}_{\mathbf{3}}$ ): Pale yellow solid; Yield: $86 \%$; m.p.: ${ }^{142-144}{ }^{\circ} \mathrm{C} ;{ }^{1} \mathrm{H}$ NMR $\left(400 \mathrm{MHz}, \mathrm{CDCl}_{3}\right): \delta=7.40-7.35(\mathrm{~m}, 4 \mathrm{H}), 7.08(\mathrm{t}$, $J=2.7 \mathrm{~Hz}, 3 \mathrm{H}), 6.87-6.81(\mathrm{~m}, 6 \mathrm{H}), 3.80(\mathrm{~s}, 3 \mathrm{H})$, 3.79 (s, 3H), 3.66 (dd, $J=3.3,11.6 \mathrm{~Hz}, \mathrm{H}-6 \mathrm{a}), 3.54$ $\left(\mathrm{d}, J=14.6 \mathrm{~Hz}, 1 \mathrm{H}\right.$ of $\left.\mathrm{N}-\mathrm{CH}_{2}\right), 3.47-3.42(\mathrm{~m}, 2 \mathrm{H}$ of $\mathrm{H}-2 \mathrm{a}$ and $1 \mathrm{H}$ of $\mathrm{N}^{-\mathrm{CH}_{2}}$ merged), $3.28(\mathrm{~d}, J=9.8 \mathrm{~Hz}$, H-3a), 2.55-2.48 (m, H-5a), 2.13 (t, $J=12.6 \mathrm{~Hz}$, $\mathrm{H}-5 \mathrm{e}) 0.75\left(\mathrm{~d}, J=6.6 \mathrm{~Hz}, \mathrm{CH}_{3}\right.$ at $\left.\mathrm{C}-3\right) \mathrm{ppm} ;{ }^{13} \mathrm{C}$ NMR (100.52 MHz, $\left.\mathrm{CDCl}_{3}\right): \delta=159.89$ (C-4), 158.94 $\left(\mathrm{C}-6^{\prime} \mathrm{c}\right), 158.80\left(\mathrm{C}-2^{\prime} \mathrm{c}\right), 137.29\left(\mathrm{C}-6^{\prime}\right), 136.15\left(\mathrm{C}-2^{\prime}\right)$, 134.49 (N-Bn ipso carbon), 129.97, 129.85, 128.84, 127.53, 126.45, 72.10 (C-2), 63.67 (C-6), 55.38 $\left(\underline{\mathrm{C}} \mathrm{H}_{3} \mathrm{O}\right.$ at $\left.\mathrm{C}-6^{\prime} \mathrm{c}, \mathrm{C}-2^{\prime} \mathrm{c}\right), 53.45\left(\mathrm{~N}-\underline{\mathrm{C}} \mathrm{H}_{2}-\mathrm{Ph}\right), 43.98$ $(\mathrm{C}-3), \quad 35.19$ (C-5), $12.81 \quad\left(\underline{C H}_{3}\right.$ at C-3) ppm; and HRMS: $\mathrm{m} / \mathrm{z}$ calculated: 430.2256, found: 430.3451 .

2.9f 1-Benzyl-2,6-bis(4-ethoxyphenyl)-3-methylpiperidin-4-one oxime (3f, $\left.\mathbf{C}_{29} \mathbf{H}_{\mathbf{3 4}} \mathbf{N}_{\mathbf{2}} \mathbf{O}_{\mathbf{3}}\right)$ : White solid; Yield: $86 \%$; m.p.: $158-160{ }^{\circ} \mathrm{C} ;{ }^{1} \mathrm{H}$ NMR $(400 \mathrm{MHz}$, $\left.\mathrm{CDCl}_{3}\right): \delta=8.89(\mathrm{~s}, \mathrm{OH}), 7.35(\mathrm{~d}, J=8.4 \mathrm{~Hz}, 4 \mathrm{H})$, $7.08(\mathrm{~s}, 3 \mathrm{H}), 6.85(\mathrm{~d}, J=6.6 \mathrm{~Hz}, 4 \mathrm{H}), 6.82-6.81(\mathrm{~m}$, 2H), 4.04-4.01 (m, 4H), $3.64(\mathrm{~d}, J=8.4 \mathrm{~Hz}, \mathrm{H}-6 \mathrm{a})$, $3.54(\mathrm{~d}, J=15.0 \mathrm{~Hz}, 1 \mathrm{H}), 3.45-3.41(\mathrm{~m}, 2 \mathrm{H}), 3.27$ $(\mathrm{d}, J=9.5 \mathrm{~Hz}, \mathrm{H}-3 \mathrm{a}), 2.50(\mathrm{t}, J=8.0 \mathrm{~Hz}, \mathrm{H}-5 \mathrm{a})$, 2.16-2.08 (m, H-5e), 1.41 (d, $J=3.2 \mathrm{~Hz}, 6 \mathrm{H}), 0.75$ (d, $J=5.4 \mathrm{~Hz}, \mathrm{CH}_{3}$ at $\left.\mathrm{C}-3\right) \mathrm{ppm} ;{ }^{13} \mathrm{C} \mathrm{NMR}(100.52 \mathrm{MHz}$, $\left.\mathrm{CDCl}_{3}\right): \delta=159.70(\mathrm{C}-4), 158.18\left(\mathrm{C}-6{ }^{\prime} \mathrm{c}\right), 158.80$ $\left(\mathrm{C}-2^{\prime} \mathrm{c}\right), 137.64\left(\mathrm{C}-6^{\prime}\right), 135.87\left(\mathrm{C}-2^{\prime}\right), 133.83$ (N-Bn ipso carbon), 129.92, 128.83, 127.52, 126.44, 114.56, 114.28, 72.04 (C-2), 63.62 (C-6), $54.13\left(\mathrm{CH}_{3} \underline{\mathrm{C}} \mathrm{H}_{2} \mathrm{O}\right.$ at C-6'c, C-2'c), $53.37\left(\mathrm{~N}-\mathrm{CH}_{2}-\mathrm{Ph}\right), 44.00(\mathrm{C}-3), 35.15$ (C-5), $15.01\left(\underline{C H}_{3} \mathrm{CH}_{2} \mathrm{O}\right.$ at C-6' $\left.\mathrm{c}, \mathrm{C}-2^{\prime} \mathrm{c}\right), 12.81\left(\underline{\mathrm{C}} \mathrm{H}_{3} b\right.$ at C-3) ppm.

2.9g 1-Benzyl-2,6-bis(4-benzyloxyphenyl)-3-methylpiperidin-4-one oxime $\left(\mathbf{3 g}, \mathbf{C}_{39} \mathbf{H}_{38} \mathbf{N}_{2} \mathbf{O}_{3}\right)$ : White solid; Yield: 93\%; m.p.: $175-177^{\circ} \mathrm{C}$; ${ }^{1} \mathrm{H}$ NMR $\left(400 \mathrm{MHz} \mathrm{CDCl}_{3}\right): \delta=8.30(\mathrm{~s}, \mathrm{OH}), 7.44-7.33(\mathrm{M}$, $14 \mathrm{H}), 7.08(\mathrm{~d}, J=2.9 \mathrm{~Hz}, 3 \mathrm{H}), 6.94(\mathrm{~d}, J=6.2 \mathrm{~Hz}$, $4 \mathrm{H}), 6.81(\mathrm{~m}, 2 \mathrm{H}), 5.05(\mathrm{~s}, 2 \mathrm{H}), 4.99(\mathrm{~s}, 2 \mathrm{H}), 3.65(\mathrm{~d}$, $J=10.2 \mathrm{~Hz}, \mathrm{H}-6 \mathrm{a}), 3.54(\mathrm{~d}, J=15.0 \mathrm{~Hz}, 1 \mathrm{H}), 3.45-$ $3.42(\mathrm{~m}, 2 \mathrm{H}), 3.29$ (d, $J=9.8 \mathrm{~Hz}, \mathrm{H}-3 \mathrm{a}), 2.53-2.49$ (m, $\mathrm{H}-5 \mathrm{a}), 2.15$ (t, $J=12.6 \mathrm{~Hz}, \mathrm{H}-5 \mathrm{e}), 0.76(\mathrm{~d}, J=6.2 \mathrm{~Hz}$, $\mathrm{CH}_{3}$ at $\left.\mathrm{C}-3\right) \mathrm{ppm} ;{ }^{13} \mathrm{C} \mathrm{NMR}\left(100.52 \mathrm{MHz}, \mathrm{CDCl}_{3}\right)$ : $\delta=159.95$ (C-4), 158.22 (C-6'c), 158.00 (C-2'c), 137.36 (N-Bn ipso carbon), 137.20 (O-Bn ipso carbon), $136.51\left(\mathrm{C}^{-} 6^{\prime}\right), 134.88\left(\mathrm{C}-2^{\prime}\right), 130.04,129.89,128.73$, 128.10, 127.71, 127.67, 127.56, 114.97, 114.69, 72.16 (C-2), $70.23\left(\mathrm{O}-\underline{\mathrm{CH}}_{2}-\mathrm{Ph}\right.$ at C-6'c, C-2'c), 63.74 (C-6), 
$54.24\left(\mathrm{~N}-\underline{C H}_{2}-\mathrm{Ph}\right), 43.96(\mathrm{C}-3), 35.15$ (C-5), 12.85 $\left(\underline{\mathrm{C}} \mathrm{H}_{3}\right.$ at $\left.\mathrm{C}-3\right) \mathrm{ppm}$.

2.9h 1-Benzyl-2,6-bis(3-methoxyphenyl)-3-methylpiperidin-4-one oxime (3h, $\left.\mathbf{C}_{\mathbf{2}} \mathbf{H}_{\mathbf{3 0}} \mathbf{N}_{\mathbf{2}} \mathbf{O}_{\mathbf{3}}\right)$ : Off-white; Yield: $79 \%$; m.p.: $128-130{ }^{\circ} \mathrm{C} ;{ }^{1} \mathrm{H}$ NMR $(400 \mathrm{MHz}$, $\left.\mathrm{CDCl}_{3}\right): \delta=7.26(\mathrm{t}, J=6.9 \mathrm{~Hz}, 3 \mathrm{H}), 7.11-7.04(\mathrm{~m}$, $6 \mathrm{H}), 6.88-6.85(\mathrm{~m}, 2 \mathrm{H}), 6.81-6.77(\mathrm{~m}, 2 \mathrm{H}), 3.82(\mathrm{~s}$, $3 \mathrm{H}), 3.81(\mathrm{~s}, 3 \mathrm{H}), 3.68(\mathrm{dd}, J=2.7,8.6 \mathrm{~Hz}, \mathrm{H}-6 \mathrm{a})$, $3.60(\mathrm{~d}, J=14.6 \mathrm{~Hz}, 1 \mathrm{H}), 3.51-3.44(\mathrm{~m}, 2 \mathrm{H}), 3.32$ (d, $J=10.24 \mathrm{~Hz}, \mathrm{H}-3), 2.59-2.51$ (m, H-5a), 2.17 (q, H-5e) 0.77 (d, $J=6.6 \mathrm{~Hz}, \mathrm{CH}_{3}$ at $\left.\mathrm{C}-3\right) \mathrm{ppm} ;{ }^{13} \mathrm{C}$ NMR (100.52 MHz, $\left.\mathrm{CDCl}_{3}\right): \delta=159.92(\mathrm{C}-4), 159.77$ $\left(\mathrm{C}-6^{\prime} \mathrm{c}\right), 159.55\left(\mathrm{C}-2^{\prime} \mathrm{c}\right), 145.71\left(\mathrm{C}-6^{\prime}\right), 144.05\left(\mathrm{C}-2^{\prime}\right)$, 136.90 (N-Bn ipso carbon), 130.03, 129.69, 129.30, $127.56,126.60,121.79,120.24,114.64,113,112.71$, 112.62, $72.52(\mathrm{C}-2), 64.04(\mathrm{C}-6), 55.33\left(2 \mathrm{O}-\underline{\mathrm{C}} \mathrm{H}_{3}\right)$, $53.82\left(\mathrm{~N}-\underline{C H}_{2}-\mathrm{Ph}\right), 43.67$ (C-3), $34.80(\mathrm{C}-5), 12.81$ $\left(\underline{C}_{3}\right.$ at $\left.\mathrm{C}-3\right) \mathrm{ppm}$.

2.9i 1-Benzyl-3-ethyl-2,6-bis(4-isopropylphenyl) piperidin-4-one oxime $\left(3 \mathbf{i}, \mathbf{C}_{32} \mathbf{H}_{40} \mathbf{N}_{2} \mathbf{O}\right)$ : White solid; Yield: $82 \%$; m.p.: $180-182{ }^{\circ} \mathrm{C}$; ${ }^{1} \mathrm{H}$ NMR $(400 \mathrm{MHz}$, $\left.\mathrm{CDCl}_{3}\right): \delta=8.16(\mathrm{~s}, \mathrm{OH}), 7.39-7.34(\mathrm{~m}, 4 \mathrm{H}), 7.15-$ $7.12(\mathrm{~m}, 4 \mathrm{H}), 7.05-7.04(\mathrm{~m}, 3 \mathrm{H}), 6.82-6.80(\mathrm{~m}, 2 \mathrm{H})$, 3.72 (dd, $J=3.3,11.3 \mathrm{~Hz}, \mathrm{H}-6 \mathrm{a}), 3.54-3.38(\mathrm{~m}, 4 \mathrm{H})$, 2.90-2.84 (m, 2H), 2.45-2.40 (m, 1H), 2.24-2.17 (m, $\mathrm{H}-5 \mathrm{e}), 1.46-1.39(\mathrm{~m}, 1 \mathrm{H}), 1.35-1.23(\mathrm{~m}, 13 \mathrm{H}), 0.76$ $(\mathrm{t}, J=7.5 \mathrm{~Hz}, 3 \mathrm{H}) \mathrm{ppm} ;{ }^{13} \mathrm{C} \mathrm{NMR}(100.52 \mathrm{MHz}$, $\left.\mathrm{CDCl}_{3}\right): \delta=158.52$ (C-4), 147.92 (C-6'c), 147.88 $\left(\mathrm{C}-2^{\prime} \mathrm{c}\right), 141.47\left(\mathrm{C}-6^{\prime}\right), 140.01\left(\mathrm{C}-2^{\prime}\right), 138.12(\mathrm{~N}-\mathrm{Bn}$ ipso carbon), 129.70, 128.95, 127.84, 127.49, 126.56, 126.58, 70.74 (C-2), 64.40 (C-6), 54.54 (C-3), 50.62 $\left(\mathrm{N}-\underline{\mathrm{C}} \mathrm{H}_{2}-\mathrm{Ph}\right), 35.24(\mathrm{C}-5), 33.90\left(\underline{\mathrm{C}} \mathrm{H}\right.$ of $\mathrm{iPr}$ at $\mathrm{C}-6^{\prime} \mathrm{c}$, $\left.\mathrm{C}-2^{\prime} \mathrm{c}\right), 24.20\left(2 \mathrm{CH}_{3}\right.$ at $\left.\mathrm{C}-6^{\prime} \mathrm{c}\right), 24.13\left(2 \mathrm{CH}_{3}\right.$ at $\left.\mathrm{C}-2^{\prime} \mathrm{c}\right)$, $20.39\left(\mathrm{CH}_{2}-\mathrm{CH}_{3}\right.$ at $\left.\mathrm{C}-3\right), 12.87\left(\mathrm{CH}_{3}\right.$ at $\left.\mathrm{C}-3\right) \mathrm{ppm}$.

2.9j 1-Benzyl-2,6-bis(4-chlorophenyl)-3-ethylpiperidin-4-one oxime $\left(\mathbf{3 j}, \mathbf{C}_{\mathbf{2 6}} \mathbf{H}_{\mathbf{2 6}} \mathbf{N}_{\mathbf{2}} \mathbf{O}\right)$ : White solid; Yield: $86 \%$; m.p.: $168-170^{\circ} \mathrm{C} ;{ }^{1} \mathrm{H}$ NMR $(400 \mathrm{MHz}$, $\left.\mathrm{CDCl}_{3}\right): \delta=7.42-7.37(\mathrm{~m}, 4 \mathrm{H}), 7.29(\mathrm{~d}, J=8.4 \mathrm{~Hz}$, 4H), 7.15-7.07 (m, 3H), 6.80-6.77 (m, 2H), 3.78 (dd, $J=3.6,11.0 \mathrm{~Hz}, \mathrm{H}-6 \mathrm{a}), 3.58-3.33$ (m, 4H), 2.38-2.33 (m, H-5e), 2.17 (q, H-5e), 1.50-1.39 (m, 1H), 1.18$1.13(\mathrm{~m}, 1 \mathrm{H}), 0.76$ (t, $J=7.3 \mathrm{~Hz}, \mathrm{CH}_{3}$ at $\left.\mathrm{C}-3\right) \mathrm{ppm}$; ${ }^{13} \mathrm{C}$ NMR $\left(100.52 \mathrm{MHz}, \mathrm{CDCl}_{3}\right): \delta=157.34$ (C-4), 142.42 (C-6'c), 141.16 (C-2'c), 136.89 (N-Bn ipso carbon), 133.14 (C-6'), 133.01 (C-2'), 130.23, 129.62, $129.10,128.91,128.64,127.83,126.81,69.75$ (C-2), $63.37(\mathrm{C}-6), 54.46\left(\mathrm{~N}-\mathrm{CH}_{2}-\mathrm{Ph}\right), 50.56(\mathrm{C}-3), 34.91$ (C-5), $20.40\left(\underline{\mathrm{CH}}_{2}\right.$ at $\left.\mathrm{C}-3\right), 12.04\left(\underline{\mathrm{CH}}_{3}\right.$ at C-3) ppm. 2.9k 1-Benzyl-2,6-bis(4-ethoxyphenyl)-3-ethylpiperidin-4-one oxime $\left(\mathbf{3 k}, \mathbf{C}_{\mathbf{3 0}} \mathbf{H}_{\mathbf{3}} \mathbf{N}_{\mathbf{2}} \mathbf{O}_{3}\right)$ : White solid; Yield: $91 \%$, m.p.: $148-150{ }^{\circ} \mathrm{C} ;{ }^{1} \mathrm{H}$ NMR $(400 \mathrm{MHz}$, $\left.\mathrm{CDCl}_{3}\right): \delta=7.36(\mathrm{q}, 4 \mathrm{H}), 7.08$ (unresolved triplet, $3 \mathrm{H}$ ), $6.84(\mathrm{~d}, J=8.8 \mathrm{~Hz}, 6 \mathrm{H}), 4.05-3.99(\mathrm{~m}, 4 \mathrm{H}), 3.72-3.67$ (m, 1H), 3.55-3.37 (m, 4H), 2.39-2.35 (m, H-5a), 2.16 $(\mathrm{t}, J=12.6 \mathrm{~Hz}, \mathrm{H}-5 \mathrm{e}), 1.42-1.38(\mathrm{~m}, 6 \mathrm{H}), 1.25-1.20$ (m, 1H), 1.18-1.13 (m, 1H), $0.75\left(\mathrm{t}, J=7.3 \mathrm{~Hz}, \mathrm{CH}_{3}\right.$ of Ethyl at C-3) ppm; ${ }^{13} \mathrm{C}$ NMR $\left(100.52 \mathrm{MHz}, \mathrm{CDCl}_{3}\right)$ : $\delta=158.24$ (C-4), 158.18 (C-6'c), 158.11 (C-2'c), $137.63\left(\mathrm{C}-6^{\prime}\right), 136.08\left(\mathrm{C}-2^{\prime}\right), 134.57$ (N-Bn ipso carbon), 129.99, 129.76, 128.82, 127.52, 126.37, 114.48, 114.18, 70.06 (C-2), 63.57 (C-6), $53.72\left(\mathrm{~N}-\underline{C H}_{2}-\mathrm{Ph}\right)$, 50.94 (C-3), 35.47 (C-5), $20.09\left(\mathrm{CH}_{3} \mathrm{CH}_{2} \mathrm{O}\right.$ at C-6'c, $\left.\mathrm{C}-2^{\prime} \mathrm{c}\right), 15.01\left(\underline{\mathrm{CH}}_{2} \mathrm{CH}_{3}\right.$ at $\left.\mathrm{C}-3\right), 12.10\left(\underline{\mathrm{C}} \mathrm{H}_{3}\right.$ at $\left.\mathrm{C}-3\right)$ ppm.

2.91 1-Benzyl-3-isopropyl-2,6-diphenylpiperidin4-one oxime (31, $\left.\mathbf{C}_{27} \mathbf{H}_{30} \mathbf{N}_{\mathbf{2}} \mathbf{O}\right)$ : Brown semi-solid; Yield: $87 \%$; ${ }^{1} \mathrm{H}$ NMR $\left(400 \mathrm{MHz}, \mathrm{CDCl}_{3}\right): \delta=7.56$ $(\mathrm{d}, J=7.3 \mathrm{~Hz}, 2 \mathrm{H}), 7.39-7.35(\mathrm{~m}, 4 \mathrm{H}), 7.28-7.24(\mathrm{~m}$, $3 \mathrm{H}), 7.18-7.09(\mathrm{~m}, 4 \mathrm{H}), 6.93(\mathrm{dd}, J=2.0,6.5,2 \mathrm{H})$, $4.31-4.22(\mathrm{~m}, 2 \mathrm{H}), 3.70(\mathrm{~d}, J=14.2 \mathrm{~Hz}, 1 \mathrm{H}), 3.55$ $(\mathrm{d}, J=14.2 \mathrm{~Hz}, 1 \mathrm{H}), 2.89-2.76(\mathrm{~m}, 2 \mathrm{H}), 2.14(\mathrm{dd}$, $J=3.1,8.9 \mathrm{~Hz}, \mathrm{H}-5 \mathrm{e}), 1.79-1.71(\mathrm{~m}, 1 \mathrm{H}), 0.96(\mathrm{~d}$, $J=6.6 \mathrm{~Hz}, 3 \mathrm{H}), 0.83(\mathrm{~d}, J=6.6 \mathrm{~Hz}, 3 \mathrm{H}) \mathrm{ppm} ;{ }^{13} \mathrm{C}$ NMR (100.52 MHz, $\left.\mathrm{CDCl}_{3}\right): \delta=157.66(\mathrm{C}-4), 145.58$ (C-6'), 144.65 (C-2'), 137.87 (N-Bn ipso carbon), 129.66, 128.80, 128.21, 127.98, 127.89, 127.35, 62.83 (C-2), 60.01 (C-6), $56.15\left(\mathrm{~N}-\underline{C H}_{2}-\mathrm{Ph}\right), 55.68$ (C-3), 35.41 (C-5), 30.15 ( $\underline{\mathrm{CH}}$ of $i \mathrm{Pr}), 21.72\left(\underline{\mathrm{CH}}_{3} \mathrm{iPr}\right) 20.63$ $\left(\underline{\mathrm{C}} \mathrm{H}_{3} \mathrm{iPr}\right) \mathrm{ppm}$.

2.9m 1-Benzyl-3,5-dimethyl-2,6-diphenylpiperidin-4one oxime ( $\mathbf{3 m}, \mathbf{C}_{\mathbf{2 6}} \mathbf{H}_{\mathbf{2}} \mathbf{N}_{\mathbf{2}} \mathbf{O}$ ): Off-white solid, Yield: 94\%; m.p.: $132-134{ }^{\circ} \mathrm{C}$; ${ }^{1} \mathrm{H}$ NMR (400 MHz, $\left.\mathrm{CDCl}_{3}\right)$ : $\delta=7.42-7.40(\mathrm{~m}, 4 \mathrm{H}), 7.34-7.11(\mathrm{~m}, 9 \mathrm{H}), 6.96(\mathrm{~d}$, $J=7.3 \mathrm{~Hz}, 2 \mathrm{H}), 4.00$ (d, $J=5.8 \mathrm{~Hz}, \mathrm{H}-6 \mathrm{a}), 3.80$ (d, $J=6.6 \mathrm{~Hz}, \mathrm{H}-2 \mathrm{a}), 3.71(\mathrm{~d}, J=14.2 \mathrm{~Hz}, 1 \mathrm{H}), 3.58-$ $3.55(\mathrm{~m}, 2 \mathrm{H}), 2.62-2.55(\mathrm{~m}, \mathrm{H}-5 \mathrm{a}), 1.24(\mathrm{~d}, J=$ $6.9 \mathrm{~Hz}, 3 \mathrm{H}), 0.98(\mathrm{~d}, J=7.3 \mathrm{~Hz}, 3 \mathrm{H}) \mathrm{ppm} ;{ }^{13} \mathrm{C} \mathrm{NMR}$ $\left(100.52 \mathrm{MHz}, \mathrm{CDCl}_{3}\right): \delta=163.05(\mathrm{C}-4), 144.57$ (C$2^{\prime} \mathrm{c}, 6^{\prime} \mathrm{c}$ ), 138.33 (N-Bn ipso carbon), 129.72, 128.48, $128.22,127.90,126.94,126.78,69.50$ (C-2), 62.11 (C-6), $57.06\left(\mathrm{~N}-\underline{C H}_{2}-\mathrm{Ph}\right), 41.87$ (C-3), 38.48 (C-5), $17.67\left(\underline{C H}_{3}\right.$ at $\left.\mathrm{C}-3\right), 16.84\left(\underline{C H}_{3}\right.$ at $\left.\mathrm{C}-5\right) \mathrm{ppm}$.

2.9n 1-Benzyl-2,6-bis(4-isopropylphenyl)-3,5-dimethylpiperidin-4-one oxime $\left(\mathbf{3 n}, \mathbf{C}_{\mathbf{3 2}} \mathbf{H}_{\mathbf{4 0}} \mathbf{N}_{\mathbf{2}} \mathbf{O}\right)$ : White solid; Yield: 92\%; m.p.: $158-160^{\circ} \mathrm{C}$; ${ }^{1} \mathrm{H} \quad \mathrm{NMR}$ $\left(400 \mathrm{MHz}, \mathrm{CDCl}_{3}\right): \delta=7.31(\mathrm{~d}, J=8.0 \mathrm{~Hz}, 4 \mathrm{H})$, 
$7.16-7.08(\mathrm{~m}, 7 \mathrm{H}), 6.93(\mathrm{~d}, J=6.9 \mathrm{~Hz}, 2 \mathrm{H}), 3.92(\mathrm{~d}$, $J=6.2 \mathrm{~Hz}, \mathrm{H}-6 \mathrm{a}), 3.79$ (d, $J=6.2 \mathrm{~Hz}, \mathrm{H}-2 \mathrm{a}), 3.69$ (d, $J=14.2 \mathrm{~Hz}, 1 \mathrm{H}), 3.57-3.51(\mathrm{~m}, 2 \mathrm{H}), 2.91-2.81(\mathrm{~m}$, two $\mathrm{CH}$ of $i \mathrm{Pr}$ ), 2.62-2.55 (m, H-5a), 1.25-1.21 $\left(\mathrm{m}, 15 \mathrm{H}\right.$ of $2\left(\mathrm{CH}_{3}\right)_{2}$ merged with $\mathrm{CH}_{3}$ at $\left.\mathrm{C}-3\right), 1.00$ $\left(\mathrm{d}, J=6.9 \mathrm{~Hz}, 3 \mathrm{H}\right.$ of $\mathrm{CH}_{3}$ at $\left.\mathrm{C}-5\right) \mathrm{ppm} ;{ }^{13} \mathrm{C} \mathrm{NMR}$ $\left(100.52 \mathrm{MHz}, \mathrm{CDCl}_{3}\right): \delta=163.05(\mathrm{C}-4), 147.42$ (C-6'c), $146.72\left(\mathrm{C}-2^{\prime} \mathrm{c}\right), 142.00\left(\mathrm{C}-6^{\prime}\right), 141.61\left(\mathrm{C}-2^{\prime}\right)$, 139.02 (N-Bn ipso carbon), 129.60, 128.28, 128.14, 127.78, 126.50, 126.40, 126.17, 69.74 (C-2), 65.62 (C-6), $56.95\left(\mathrm{~N}-\underline{C}_{2}-\mathrm{Ph}\right), 42.00(\mathrm{C}-3), 38.56(\mathrm{C}-5)$, 33.88 (2대 $i P r), 33.78(2 \underline{C} \mathrm{H} i P r), 24.20 \quad\left(4 \underline{C} \mathrm{H}_{3}\right.$ $i P r), \quad 18.16\left(\underline{C H}_{3}\right.$ at $\left.\mathrm{C}-3\right), 16.70 \quad\left(\underline{C} \mathrm{H}_{3}\right.$ at $\left.\bar{C}-5\right)$ ppm.

2.9o 1-Benzyl-2,6-bis(4-ethoxyphenyl)-3,5-dimethylpiperidin-4-one oxime $\left(\mathbf{3 o}, \mathbf{C}_{\mathbf{3 0}} \mathbf{H}_{\mathbf{3 6}} \mathbf{N}_{\mathbf{2}} \mathbf{O}_{3}\right)$ : White solid; Yield: $88 \%$; m.p.; $172-174{ }^{\circ} \mathrm{C} ;{ }^{1} \mathrm{H}$ NMR (400 $\left.\mathrm{MHz}, \mathrm{CDCl}_{3}\right): \delta=8.28(\mathrm{~s}, \mathrm{OH}), 7.28(\mathrm{t}, J=8.6 \mathrm{~Hz}$, $4 \mathrm{H}), 7.15-7.08(\mathrm{~m}, 3 \mathrm{H}), 6.94(\mathrm{~d}, J=5.8 \mathrm{~Hz}, 2 \mathrm{H})$, $6.85(\mathrm{~d}, J=8.4 \mathrm{~Hz}, 2 \mathrm{H}), 6.77(\mathrm{~d}, J=8.8 \mathrm{~Hz}, 2 \mathrm{H})$, 4.05-3.96 (m, 4H), 3.91 (d, $J=6.2 \mathrm{~Hz}, \mathrm{H}-6 \mathrm{a}), 3.78$ $(\mathrm{d}, J=6.9 \mathrm{~Hz}, \mathrm{H}-2 \mathrm{a}), 3.69(\mathrm{~d}, J=14.3 \mathrm{~Hz}, 1 \mathrm{H})$, 3.55-3.49 (m, 2H), 2.59-2.52 (m, H-5a), 1.42-1.37 (m, $6 \mathrm{H}$ of $\left.2 \mathrm{CH}_{3} \mathrm{CH}_{2} \mathrm{O}\right), 1.22\left(\mathrm{~d}, J=7.3 \mathrm{~Hz}, 3 \mathrm{H}\right.$ of $\mathrm{CH}_{3}$ at $\mathrm{C}-3), 0.97\left(\mathrm{~d}, J=6.9 \mathrm{~Hz}, 3 \mathrm{H}\right.$ of $\mathrm{CH}_{3}$ at C-3) ppm; ${ }^{13} \mathrm{C}$ NMR (100.52 MHz, $\left.\mathrm{CDCl}_{3}\right): \delta=163.45(\mathrm{C}-4), 158.19$ $\left(\mathrm{C}-66^{\prime} \mathrm{c}\right), 157.86\left(\mathrm{C}-2^{\prime} \mathrm{c}\right), 138.95\left(\mathrm{C}-6^{\prime}\right), 136.62\left(\mathrm{C}-2^{\prime}\right)$, 136.39 (N-Bn ipso carbon), 129.61, 129.22, 127.83, 126.60, 69.27 (C-2), 64.87 (C-6), $63.48\left(\mathrm{O}_{\underline{C}} \mathrm{H}_{2}\right)$, $63.44\left(\mathrm{O}_{\underline{C}} \mathrm{H}_{2}\right), 56.81\left(\mathrm{~N}-\underline{C}_{2}-\mathrm{Ph}\right), 42.06(\mathrm{C}-3), 38.57$ (C-5), $17.77\left(\underline{\mathrm{CH}}_{3}\right.$ at $\left.\mathrm{C}-3\right), 16.77\left(\underline{\mathrm{C}} \mathrm{H}_{3}\right.$ at $\left.\mathrm{C}-5\right), 15.04$ $\left(\underline{C} \mathrm{H}_{3} \mathrm{CH}_{2} \mathrm{O}\right.$ at $\left.\mathrm{C}-6^{\prime} \mathrm{c}, \mathrm{C}-2^{\prime} \mathrm{c}\right) \mathrm{ppm}$.

\section{Results and discussion}

\subsection{Chemistry}

The highly functionalized 1-benzyl-3,5-dialkyl-2,6diarylpiperidin-4-one oximes $\mathbf{3 a - 0}$ were synthesized using appropriate piperidin-4-ones, ${ }^{18,19}$ sodium acetate trihydrate and hydroxylamine hydrochloride in ethanol as shown in scheme 1 . It is interesting to note that it took only $1-2 \mathrm{~h}$ for the i-Pr and Cl-phenyl containing N-benzylpiperidin-4-ones to be converted to oximes, while the reaction time for the alkoxy-phenyl containing N-benzylpiperidin-4-ones was much longer, about $5 \mathrm{~h}$. The synthesized compounds were characterized by ${ }^{1} \mathrm{H} /{ }^{13} \mathrm{C}$ NMR and single-crystal X-ray diffraction studies. All the synthesized oximes from unsymmetrical ketones existed as E-isomer as witnessed by their NMR and XRD data.
Single-crystal X-ray diffraction analysis has been performed representatively for the 3-methyl and 3,5dimethyl compounds $3 \mathbf{d}$ and $\mathbf{3 n}$. The puckering parameters of the compounds were analysed according to Cremer and Pople and Nardelli. ${ }^{14,15}$ For the piperidone ring C1-C2-C3-C4-C5-N1 of 3d, the smallest displacement asymmetry parameters $\mathrm{q}_{2}$ and $\mathrm{q}_{3}$ are 0.0911 and $-0.5598 \AA$, respectively. The ring puckering parameters such as total puckering amplitude ' $Q_{T}$ ' and phase angle ' $\theta$ ' are $0.5670 \AA$ and $169.37^{\circ}$. Thus, all puckering parameters strongly support a slightly distorted chair conformation for the piperidone ring.

The stereochemistry of the substituents are analysed as follows. The equatorial orientation of the methyl group is witnessed by its torsion angles $177.4^{\circ}[\mathrm{C} 2$ C3-C4-C12] and $176.9^{\circ}$ [N1-C1-C2-C12]. The torsion angles of the phenyl groups on both sides of the amino group are $171.8^{\circ}$ [C3-C2-C1-C6] and $-178.4^{\circ}$ [C3-C4C5-C13], which support their equatorial orientation. The ' $N$ ' atom of the piperidone molecule shows the $\mathrm{sp}^{3}$ hybridization, which can be evidenced from the angles around that nitrogen. The N-benzyl group also adopts an equatorial disposition to the best plane of the piperidone ring, which is evidenced from the torsion angles C19-N1-C5-C4 = 178.4 ${ }^{\circ}$ and C19-N1-C1-C2 = $-176.9^{\circ}$. X-ray analysis of $\mathbf{3 d}$ revealed the conformation of the molecule with $\mathrm{C} 1, \mathrm{C} 2$ and $\mathrm{C} 5$ having $\mathrm{R}$, $\mathrm{R}$ and $\mathrm{S}$ relative configurations, respectively. Overall, the detailed crystallographic studies such as asymmetry parameters, ring puckering parameters and torsion angles calculated for $\mathbf{3 d}$ proved that the piperidone ring exists in a slightly distorted chair conformation with an equatorial orientation of the methyl group on one of the active methylene centres and phenyl rings on both sides of the tertiary amino group along with an equatorial orientation of the benzyl group on the tertiary amino group. ORTEP of the compound $\mathbf{3 d}$ is shown in figure 2.

Single-crystal analysis of $\mathbf{3 n}$ clearly indicates that the molecule exist in a twist-boat conformation with $\mathrm{R}, \mathrm{R}$, $\mathrm{S}$ and $\mathrm{S}$ relative configurations of $\mathrm{C} 1, \mathrm{C} 2, \mathrm{C} 4$ and $\mathrm{C} 5$, respectively. The ring puckering parameters ' $Q_{T}$ ' and ' $\theta$ ' are $0.7687 \AA$ and $89.38^{\circ}$. ORTEP of the compound $\mathbf{3 n}$ is shown in figure $3 .^{21,22}$

\subsection{Cytotoxicity}

All the synthesized compounds $\mathbf{3 a - 0}$ were subjected to MTT assay to evaluate in vitro cytotoxicity against HeLa cells. ${ }^{23}$ The $\mathrm{IC}_{50}$ values of all compounds are summarized along with their structure in table 1 for better structure activity comprehension. Besides, the standard drugs camptothecin and etoposide, ${ }^{24-27}$ were 
<smiles>[R7]CC(=O)C[R7]=C[CH-]C(=O)c1ccc([R])c([R7])c1</smiles><smiles>[R]c1ccc(C2C([R])C(=NO)C([R])C(c3ccc([R])c([R7])c3)N2Cc2ccccc2)cc1[R]</smiles>

(Yield: 80-90\%)

Scheme 1. Reagents and conditions: (a) Ethanol, warm. (b) Benzyl bromide, anhydrous $\mathrm{K}_{2} \mathrm{CO}_{3}, \mathrm{THF}, \mathrm{rt}, 72 \mathrm{~h}$. (c) Hydroxylamine hydrochloride, sodium acetate trihydrate, ethanol, reflux, 1-5 h.

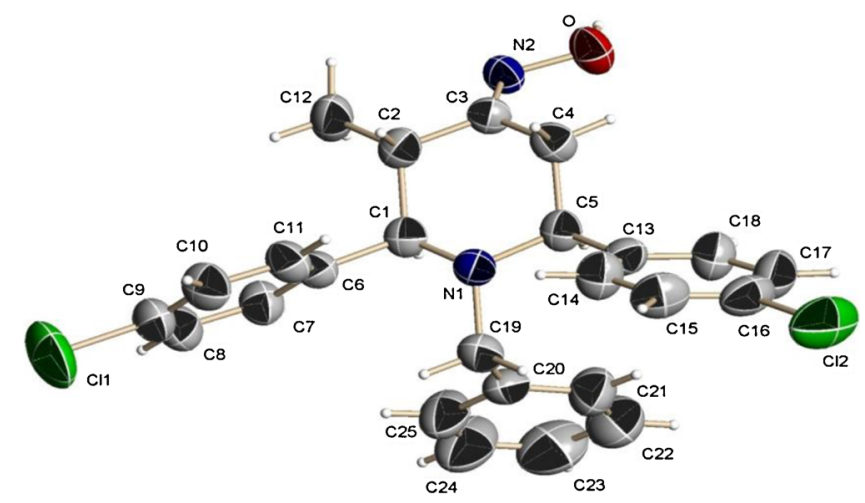

Figure 2. The ORTEP of compound 3d. Ellipsoids are drawn at $50 \%$ probability. Crystal analysis clearly proved that the oxime adopts the $E$ configuration.

also analysed under identical conditions and their $\mathrm{IC}_{50}$ values are also reproduced in the table 1.

Analyses of the cytotoxic data from table 1 project some lead molecules. All the tested compounds 3a-o exhibited good antiproliferative activity against the cancer cells with $\mathrm{IC}_{50}$ values ranging from 13.88 to $37.94 \mu \mathrm{M}$ concentration except compound $\mathbf{3 g}$, which required $93.91 \mu \mathrm{M}$. Among them, compounds 3a, 31

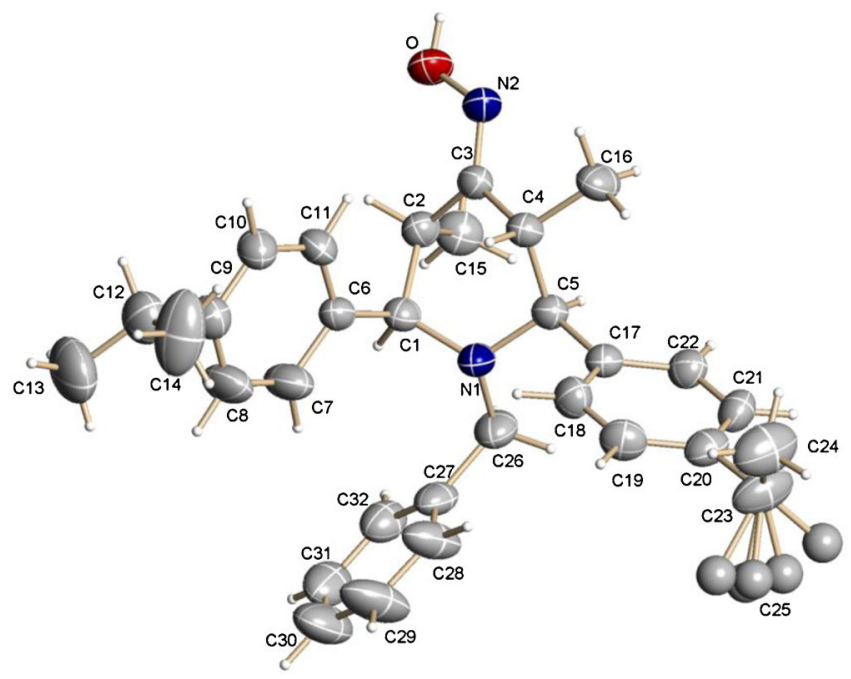

Figure 3. The ORTEP of compound 3n. Ellipsoids are drawn at $40 \%$ probability. One of the methyl atoms C25 is disordered in five different positions with 0.2 occupancy. The C25 atom has been refined isotropically and no hydrogen atoms were fixed for this atom.

and 3m with unsubstituted phenyl groups on both sides of the tertiary amino group have shown lesser activity (25.23, 34.63 and $37.94 \mu \mathrm{M}$, respectively) than their 
Table 1. ${ }^{a}$ Cytotoxic effect of compounds 3a-o on HeLa cells.

\begin{tabular}{|c|c|c|c|c|}
\hline Compound & Structure & $\begin{array}{c}{ }^{\mathrm{b}} \text { Linear regression equation } \\
{ }^{\mathrm{a}}[\log ]: \mathrm{Y}=\mathrm{A}+\mathrm{Bx}\end{array}$ & $R$ value & ${ }^{\mathrm{c}} \mathrm{IC}_{50}$ in $\mu \mathrm{M}$ \\
\hline $3 \mathbf{a}$ & & $\mathrm{Y}=9.97629+(41.34597) \mathrm{x}$ & 0.98 & $25.23 \pm 3.8$ \\
\hline $3 \mathbf{b}$ & & $Y=-0.90241+(50.11737) x$ & 0.93 & $25.98 \pm 2.04$ \\
\hline $3 c$ & & $\mathrm{Y}=12.19751+(47.24709) \mathrm{x}$ & 0.98 & $13.88 \pm 0.93$ \\
\hline 3d & & $\mathrm{Y}=4.93121+(52.61212) \mathrm{x}$ & 0.97 & $16.39 \pm 2.47$ \\
\hline $3 \mathbf{e}$ & & $Y=8.459+(43.24166) x$ & 0.98 & $21.21 \pm 1.42$ \\
\hline $3 f$ & & $\mathrm{Y}=17.6655+(37.30817) \mathrm{x}$ & 0.98 & $16.10 \pm 3.06$ \\
\hline $3 g$ & & $Y=-35.01759+(55.23339) x$ & 0.96 & $93.91 \pm 3.38$ \\
\hline $3 h$ & & $Y=-17.78817+(57.67985) x$ & 0.94 & $32.17 \pm 2.37$ \\
\hline
\end{tabular}


Table 1. (contd.)

\begin{tabular}{|c|c|c|c|c|}
\hline Compound & Structure & $\begin{array}{c}{ }^{\mathrm{b}} \text { Linear regression equation } \\
{ }^{\mathrm{a}}[\log ]: \mathrm{Y}=\mathrm{A}+\mathrm{Bx}\end{array}$ & $R$ value & ${ }^{\mathrm{c}} \mathrm{IC}_{50}$ in $\mu \mathrm{M}$ \\
\hline $3 \mathbf{i}$ & & $Y=0.59467+(47.01865) x$ & 0.95 & $23.60 \pm 1.20$ \\
\hline 3j & & $Y=-5.928+(56.84707) x$ & 0.95 & $21.28 \pm 2.13$ \\
\hline $3 \mathbf{k}$ & & $\mathrm{Y}=3.46962+(45.80483) \mathrm{x}$ & 0.98 & $22.07 \pm 3.4$ \\
\hline 31 & & $\mathrm{Y}=-29.78378+(67.83093) \mathrm{x}$ & 0.94 & $34.63 \pm 1.43$ \\
\hline $3 \mathbf{m}$ & & $Y=-32.48966+(68.4888) x$ & 0.95 & $37.94 \pm 1.32$ \\
\hline $3 n$ & & $Y=7.52381+(48.38217) x$ & 0.99 & $16.08 \pm 1.43$ \\
\hline 30 & & $Y=10.47483+(44.62101) x$ & 0.96 & $16.23 \pm 1.65$ \\
\hline $\begin{array}{l}\text { Etoposide } \\
\text { Camptothecin }\end{array}$ & & $\begin{array}{c}Y=2.27708+(41.80905) x \\
Y=29.02966+(42.56504) x\end{array}$ & $\begin{array}{l}0.98 \\
0.99\end{array}$ & $\begin{array}{c}23.33 \pm 0.92 \\
8.93 \pm 0.54\end{array}$ \\
\hline
\end{tabular}

${ }^{a}$ Exponentially growing cells were treated with different concentrations of test compounds for $24 \mathrm{~h}$ and cell growth inhibition was analysed through MTT assay

${ }^{\mathrm{b}}$ Structure drawn on the basis of found relative configuration using Single-crystal XRD analysis (3d and 3n) and 1D NMR ${ }^{\mathrm{c}}$ Mean percent decrease in cell number of five independent experiments was used to calculate the linear regression equation. Linear regression: $\mathrm{Y}=\mathrm{A}+\mathrm{Bx}(\mathrm{A}=\mathrm{Y}$-intercept; $\mathrm{B}=$ slope of the line; $\mathrm{x}=\mathrm{x}$-scale $)$

${ }^{\mathrm{d}} \mathrm{IC}_{50}$ is defined as the concentration, which results in a $50 \%$ decrease in cell number as compared with that of the control cultures in the absence of an inhibitor. The values represent the mean \pm SD of five individual observations 
analogues halo/alkyl/alkoxy substituted phenyl compounds. Compounds 3c, 3d and $\mathbf{3 f}$ with isopropyl, ethoxy and chloro substituents on the phenyl groups at C-2/C-6 along with the methyl at C-3 showed their best activity, below the $\mathrm{IC}_{50}$ of $16.39 \mu \mathrm{M}$. Of them, particularly compound $\mathbf{3 c}$, the para-iPr-phenyl compound registered the best activity in this series, which inhibited the proliferation of cancer cells with an $\mathrm{IC}_{50}$ of $13.88 \mu \mathrm{M}$.

In addition to the methyl group at C-3, one more methyl group was introduced on another active methylene centre at C-5. On the other hand, to improve the efficacy, we replaced the methyl group at C-3 by the ethyl and isopropyl groups. However, either the replacement of methyl at C-3 by ethyl and isopropyl or incorporation of another methyl at C-5 did not improve the efficacy of compounds 3c, 3d and 3f. Instead, the 3-ethylated analogues (3i, $\mathbf{3} \mathbf{j}$ and $\mathbf{3 k}$, respectively) of $\mathbf{3 c}, \mathbf{3 d}$ and $\mathbf{3 f}$ required the $\mathrm{IC}_{50}$ between 21.28 and $23.60 \mu \mathrm{M}$, and the 3,5-dimethylated analogs 3n $(16.08 \mu \mathrm{M})$ and $30(16.23 \mu \mathrm{M})$ exhibited a similar range of cytotoxicity. Overall, many compounds viz., $\mathbf{3 c}-\mathbf{f}, \mathbf{3} \mathbf{j}-\mathbf{k}$ and $\mathbf{3 n}-\mathbf{0}$ are better than one of the standard drugs Etoposide $(23.33 \mu \mathrm{M})$ and $\mathbf{3 c}$ is comparable to another anticancer drug camptothecin $(8.93 \mu \mathrm{M})$ under identical conditions. As a reference, MTT assay was also performed with lead test compounds using normal healthy PBMCs (peripheral blood mononuclear cell). There was no significant indication of cell death in these cells even at higher concentration $(100 \mu \mathrm{M})$ of the test compounds. This confirmation of non-toxicity on healthy cells can be a chemotherapeutic measure to propose these compounds as medicinally important drug leads. The $\mathrm{IC}_{50}$ (inhibition of cell viability to $50 \%$ ) concentrations were calculated using the respective regression equation as shown in table 1 and figure 4 .

\subsection{Altered morphology study}

The altered morphology of exposed cells $\left(1 \times 10^{5}\right.$ cells/well) at $\mathrm{IC}_{50}$ concentration was studied after $24 \mathrm{~h}$ using phase contrast microscope (DMI6000B, Leica Microsystems, Wetzlar, Germany) and manifested in the figure 5.

The altered morphology of the cells as a rejoinder to the effect of test compounds was observed under a phase-contrast microscope. The group that lacks the test compound was considered as control. As depicted in figure 5a, all the control cells have shown normal healthy and intact nuclei without any cytological abnormalities (figure 5a). The remaining cells were treated with $\mathrm{IC}_{50}$ concentration of highly toxic test compound $3 \mathbf{c}$ for $24 \mathrm{~h}$. Number of cytomorphological anomalies were observed in the test group viz., blebbing of cellular membrane, chromatin condensation, fragmentation
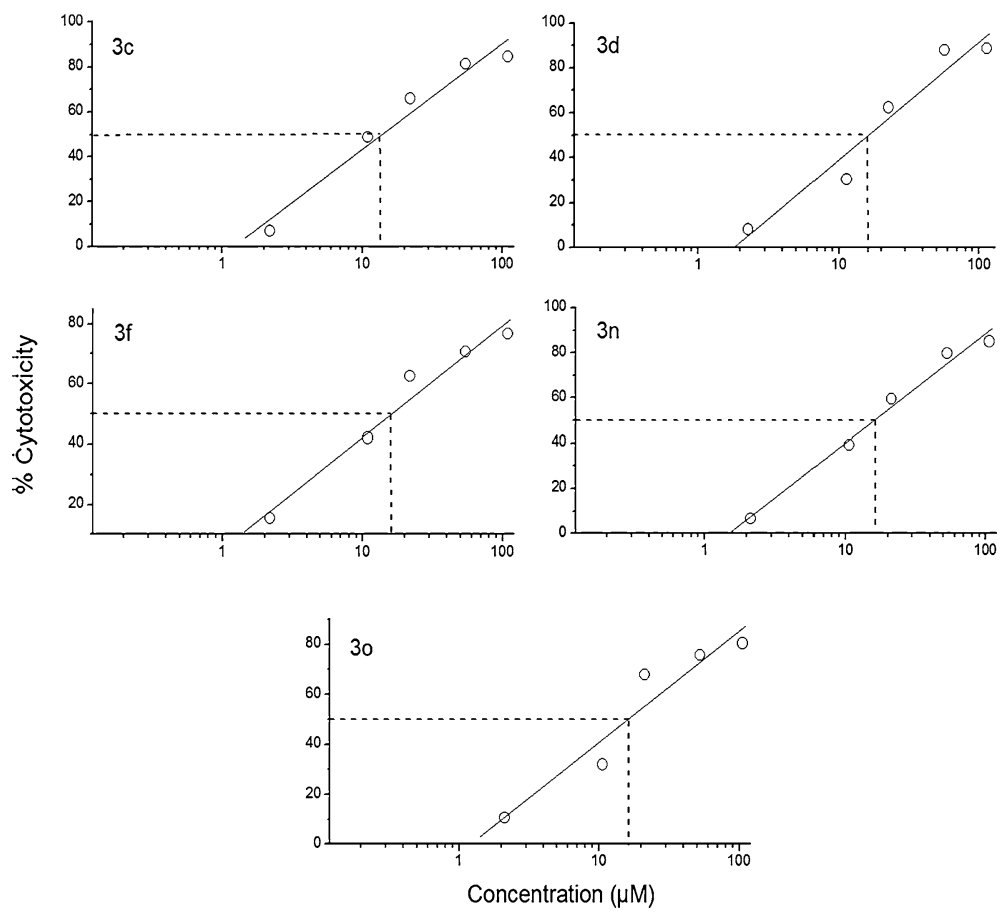

Figure 4. The graphs of linear regression analysis representing the growth inhibition of different test compounds with $\mathrm{IC}_{50}$ values below $20 \mu \mathrm{M}$. 

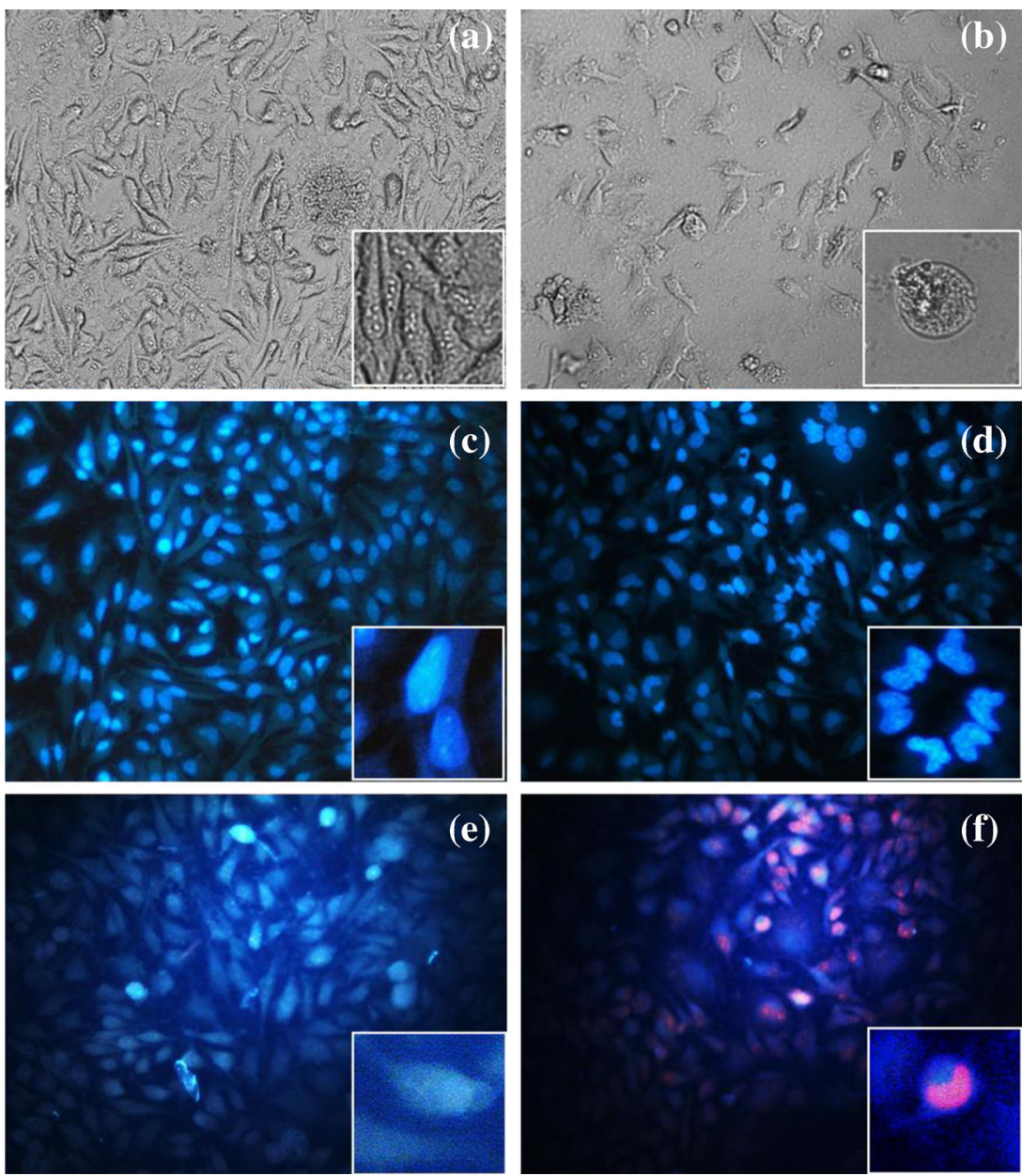

Figure 5. Light and fluorescent micrographs of normal and treated HeLa cells. Phase contrast micrographs of normal and treated (with the $\mathrm{IC}_{50}$ concentration of ideal compound $\mathbf{3 c}$ for $24 \mathrm{~h}$ ) HeLa cells (a and $\mathbf{b}$, respectively). Fluorescence micrographs of normal and treated (with the $\mathrm{IC}_{50}$ concentration of ideal compound 3c for 24 h) HeLa cells with Hoechst 33342 stain (c and d, respectively) and Propidium Iodide (e and f, respectively). The stained cells were detected by fluorescence light microscope at 360/470 nm and 535/617 nm excitation/emission for Hoechst stain and PI, respectively. Each inset represents the magnified image of the corresponding normal and deformed cell/nuclei.

and formation of apoptotic bodies (figure 5b). Most of the treated cells exhibited the symptoms of apoptosis but the damage was intense in some cells, with the cell membrane rupture and the subsequent release of cytoplasm as observed in figure $5 \mathrm{~b}$ (inset). To confirm the light microscopy data and to visualize dead cells in a more proper manner, the cells were exposed to fluorescence microscopy using Hoechst 33342 and PI stains for control and treated cells (figure $5 \mathrm{c}$ and d, respectively). Obviously, the bright condensed chromatin was identified, leading to the deformed nuclear cytoplasmic consistency followed by the margination of chromatin into a horseshoe shaped structure which was a clear indication of early apoptosis (figure $5 \mathrm{~d}$, inset) for the cells treated with the same concentration as described above. The destructive fragmentation of the nucleus (karyorrhexis) resulted in the picknosis of the treated cells. ${ }^{27,28}$ When stained with PI, the dead cells took up the stain to give a clear quantitative picture of the cytotoxic effect of the test compound at its $\mathrm{IC}_{50}$ concentration. It is noteworthy here that only the dead cells take up PI staining thus allowing a better visual analysis of the toxicity of the test compound.

\subsection{Annexin V-PI dual staining to access appotosis}

Fluorescence microscopy is a wonderful tool to access cellular processes and the corresponding morphological 

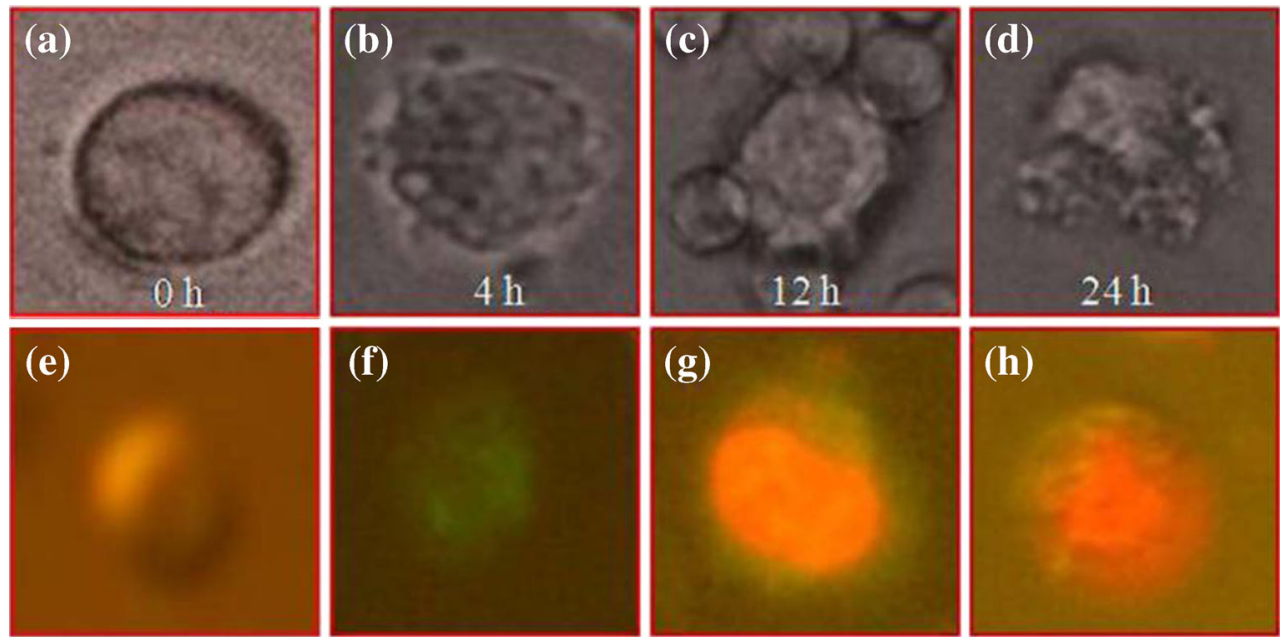

Figure 6. Annexin V-FITC/PI dual staining to access the degree of apoptosis. Phase contrast $(\mathbf{a}-\mathbf{d})$ and fluorescence $(\mathbf{e}-\mathbf{h})$ micrographs of control and $\mathbf{3 c}(13.88 \mu \mathrm{M})$ treated HeLa cells.

changes occurring in the cells in response to external stimuli. HeLa cells untreated and treated with $13.88 \mu \mathrm{M}$ lead compound $3 \mathrm{C}$ were stained with Annexin V labelled with FITC and counter stained with PI after different time intervals $(0,4,12,24 \mathrm{~h})$. Annexin $\mathrm{V}$ specifically binds to the phosphatidylserine in the cells, marking its relocation to the outercell membrane and PI enters only dead cells as it cannot pass through the intact cell membrane. Dual staining with Annexin V-FITC and PI simultaneously, gives a clear indication of early/late apoptosis (with exposure of phosphatidylserine) and cell death. Our results showed marked apoptosis of 3C treated HeLa cells in a time dependent manner (figure 6). Early apoptosis after $4 \mathrm{~h}$ of treatment is depicted in figure $6 \mathrm{f}$ when the cells are stained with FITC alone whereas late apoptosis (12 h post treatment) marked the staining with both green FITC and red PI thus giving a yellowish (figure $6 \mathrm{~g}$ ). However, at the end of $24 \mathrm{~h}$, a large number of PI stained cells with red fluorescence were observed indicating cell death (figure 6h).

\section{Conclusion}

All the synthesized novel N-benzylpiperidin-4-one oxime molecules were screened for their anticancer activity against HeLa cells. This effort has led to the identification of five new compounds $\mathbf{3 c}, \mathbf{3 d}, \mathbf{3 f}, \mathbf{3 n}$ and 30 with effective $\mathrm{IC}_{50}$ of 13.88 to $16.39 \mu \mathrm{M}$. Of them, 1benzyl-2,6-bis(4-isopropylphenyl)-3-methylpiperidin4-one oxime $3 \mathbf{c}$ with an $\mathrm{IC}_{50}$ of $13.88 \mu \mathrm{M}$ was found to be the best active compound.

\section{Supplementary information}

Crystallographic data of compounds 3d (CCDC No. 841850) and 3n (CCDC No. 841849) are provided as supplementary material. Supplementary crystallographic data for 3d and $\mathbf{3 n}$ can be obtained free of charge at www.ccdc.cam.ac.uk/conts/retrieving.html.

\section{Acknowledgements}

This research was supported by Second Phase of Brain Korea (BK21) Program.

\section{References}

1. Parkin D M 2006 Int. J. Cancer 1183030

2. Canavan T P and Doshi N R 2000 Am. Fam. Physician 611369

3. Marrazzo J M, Koutsky L A, Kiviat N B, Kuypers J M and Stine K 2001 Am. J. Public Health 91947

4. Gibbs J B 2000 Science 2871969

5. Varmus H 2006 Science $\mathbf{3 1 2} 1162$

6. Dimmock J R, Padmanilayam M P, Puthucode R N, Nazarali A J, Motaganahalli N L, Zello G A, Quail J W, Oloo E O, Kraatz H B, Prisciak J S, Allen T M, Santos C L, Balzarini J, Clercq E D and Manavathu E K 2001 J. Med. Chem. 44586

7. Kalai T, Kuppusamy M L, Balog M, Selvendiran K, Rivera B K, Kuppusamy P and Hideg K $2011 \mathrm{~J}$. Med. Chem. $\mathbf{5 4} 5414$

8. Selvendiran Tong L, Bratasz A, Kuppusamy M L, Ahmed S, Ravi Y, Trigg N J, Rivera B K, Kálai T, Hideg $\mathrm{K}$ and Kuppusamy P $2010 \mathrm{Mol}$. Cancer Ther. 91169

9. El-Subbagh H I, Abu-Zaid S M, Mahran M A, Badria F A and Al-Obaid A M 2000 J. Med. Chem. 432915 
10. Parthiban P, Pallela R, Kim S K, Park D H and Jeong Y T 2011 Bioorg. Med. Chem. Lett. 216678

11. Dimmock J R, Elias D W, Beazely M A and Kandepu N M 1999 Curr. Med. Chem. 61125

12. Dimmock J R, Kandepu N M, Nazarali A J, Kowalchuk T P, Motaganahalli N, Quail J W, Mykytiuk P A, Audette G F, Prasad L, Perjési P, Allen T M, Santos C L, Szydlowski J, De Clercq and Balzarini $1358 \mathrm{~J}$. Med. Chem. 42.

13. Bill M A, Bakan C Jr, Benson D M, Fuchs J, Young G and Lesinski G B 2009 Mol. Cancer Ther. 82726

14. Bruker, SMART, SAINT, Bruker AXS, Inc., Madison, Wisconsin, USA, 1998

15. Sheldrick G M 2008 Acta Crystallogr. A64 112

16. Noller C R and Baliah V 1948 J. Am. Chem. Soc. 70 3853

17. Dindulkar S D, Parthiban P and Jeong Y T 2012 Monatsh. Chem. 143113
18. Dindulkar S D, Parthiban P, Purnik V G and Jeong Y T 2011 J. Mol. Struct. 99044

19. Dindulkar S D, Parthiban P, Purnik V G and Jeong Y T 2012 J. Mol. Struct. 1007158

20. Boyum A 1968 Scand. J. Clin. Lab. Invest. 2177

21. Cremer D and Pople J A 1975 J. Am. Chem. Soc. 97 1354

22. Nardelli M 1983 Acta Crystallogr. C39 1141

23. Mosmann T 1983 J. Immunol. Methods 6555

24. Jeon S J, Seol J E, Yang S I, Choi J W, Wells D, Shin C Y and Kwang K 2011 J. Biomed. Sci. 1817

25. Roopan S M and Khan F N 2009 Arkivoc 13161

26. Al-Saleh E, Hoskins P J, Pike J A and Swenerton K D 1997 Gynecol. Oncol. 64468

27. Potmesil M 1994 Cancer Res. 541431

28. Arepalli S K, Sridhar V, Rao J V, Kennady P K and Venkateswarlu Y 2009 Apoptosis 14729 